\title{
Calibration the area-reduction method in sediment distribution of Ekbatan reservoir dam using genetic algorithms
}

\author{
Sepideh Torabi ${ }^{1} \cdot$ Hojjat Allah Yonesi $^{1} \cdot$ Babak Shahinejad $^{1}$
}

Received: 19 June 2015/Accepted: 7 August 2015/Published online: 14 August 2015

(C) Springer International Publishing Switzerland 2015

\begin{abstract}
Dam reservoirs usually play the most important role in the water resources systems and their optimal utilization in economic and social terms is indispensable. Sedimentation in dam's reservoirs is one of the destructive phenomena which leads to reduction of useful volume of reservoirs and also damages the installations and disturbs their functions. Area reduction method is the most common experimental method to measure the sediment distribution in reservoirs. In this method, reservoirs are geometrically divided into four types. Parameters obtained for each type are based on limited number of chosen reservoirs and consequently the results lead to large scale errors for accuracy of this method. Therefore choosing appropriate parameters can help us to have more acceptable accuracy. In this study, first based on area reduction method a model was made by using MATLAB software and optimized by GA. Error declined by $46.7 \%$. Then elevation-area-capacity curves for following years were predicted by best coefficients.
\end{abstract}

Keywords Area reduction method - Genetic algorithms . Sediment distribution - Optimization · Ekbatan dam

\section{Introduction}

Rivers have fascinated humanity for centuries. Most prosperous cities around the world have been founded along rivers (Pierre 2002). In ancient times, dams were built for

Sepideh Torabi

torabi_3pd@yahoo.com

1 Department of Water Engineering, College of Agriculture, Lorestan University, Lorestan, Iran the single purpose of water supply or irrigation. As civilizations developed, there was a greater need for water supply, irrigation, flood control, navigation, water quality, sediment control and energy. Building a dam on the river reduces water velocity and increases water level in dam's upstream. These factors have important effects on changing river morphology and increasing sediments in dam's reservoir.

Each year approximately 20 billion tons of sediment, moved by the world's rivers and waters, are resident deposits (Shafiee and Safamehr 2011). When the current velocity behind the dam reduces, transported sediments in river upstream start to settle in the reservoir. One of the destructive results of sedimentation in the reservoir is the reduction of its stability. Flood due to dam failure can cause catastrophic damage of properties and loss of life (Wu 2007). Sedimentation behind the dam will have negative effects on the exit installations and gates as well. These destructive effects endanger dam's safety (Mohammadzadeh Habili and Mousavi 2008). In sum, sedimentation in dam's reservoirs reduces the useful volume of the reservoir and consequently reduces dam's shelf life (Jain 2003). Therefore prediction and estimation of sediment transportation amount is very important (Shafai Bajestan 2011).

One of the most current methods of measuring the volume difference in a reservoir is using the elevationarea-capacity curves (Lara 1971). Experimental method of area reduction can be mentioned as one of the Elevationarea-capacity curves to distinguish the sediment distribution manner. Several studies have been conducted on experimental method. Area reduction method was evaluated by comparing resurvey data for a number of South African reservoirs with calculated values. The sediment which accumulated in these reservoirs varies from 1.14 to 
$44.94 \%$, representing a wide range of conditions. The test was carried out for each reservoir by calculating the empirical sediment distribution of all four standard reservoir types, whereafter the type which most closely fitted the observed data was determined. This was accomplished by calculating the sum of the squares of the differences between the observed and empirical curves and taking the volume/depth and surface area/depth curves with the smallest sums as having the best fit (Annandale 1984). Ferrari estimated the sediment distribution of Prineville reservoir using area reduction method (Ferrari 1998).

Since the parameters used in the area reduction method are only based on information from limited numbers of dams in US and using this information is very important in accuracy of this method, hence it is possible that parameters used in this method can not be appropriate for prediction of sediment distributions in another reservoir elsewhere. Thus changing these parameters in every reservoir can help us to have more accurate prediction of sediment distribution. Having known the quality of sediment distribution and prediction, we can choose the policies of exploiting the reservoir and decision making about the problems caused by sediments with higher confidence. Sediment settlement is not uniform.

The area reduction method was manually calibrated for Golestan dam resulting to a $10 \%$ reduction on error of estimation (Mohammadiha et al. 2010). The sediment distribution behind the Zayanderood dam was investigated using area increment and area reduction methods and comparing the results of models with the distribution of sediment settlement in the reservoir showed that Borland and Miller model of area reduction method has the highest similarity to real sediment distribution discrepancy (Mousavi et al. 2006). The exact data of elevation volume of Droodzan dam as well as the primary data were used to calibrate the parameters of the area reduction technique for the reservoir. Thus, through calibrating the parameter caused a $30 \%$ reduction in the error of estimating the amount and profile of sediment distribution (Gharaghezlou et al. 2014). The area reduction method was calibrated using simulating annealing (SA) for Karaj dam and Error declined by $20 \%$ (Emadi et al. 2012).

In order to estimate sediments distribution manner by area reduction parameters will be calculated carefully by optimization method. In recent years, some optimization methods that are conceptually different from the traditional mathematical programming techniques have been developed (Engelbrecht 2002). This methods are labeled as modern or nontraditional methods of optimization (Pelikan et al. 1999). One of these methods are genetic algorithms (GAs). GAs are well suited for solving such problems, and in must cases they can find the global optimum solution with a high probability. The genetic algorithm (GA) is an optimization and search technique based on the principles of genetics and natural selection (Vose 1999). A GA allows a population composed of many individuals to evolve under specified selection rules to a state that maximizes the "fitness" (i.e., minimizes the cost function). The method was developed by Holland (1975) over the course of the 1960s and 1970s and finally popularized by one of his students, David Goldberg. Philosophically, GAs are based on Darwin's theory of survival of the fittest (Haupt and Haupt 2004).

The aim of this research is to optimize area reduction method parameters by using genetic algorithms and to increase the accuracy of this method by in estimating sediment distribution in reservoirs for coming years.

In this study, first based on area reduction method a model was made by using MATLAB software and calibrated by GA. Then sediment distribution profile of 2012 was estimated through area reduction method before and after calibration.

\section{Materials and methods}

\section{Study area}

Ekbatan dam is one of the most important dams of the west region of Iran. It is situated $10 \mathrm{~km}$ southeast of Hamedan city on the Abshineh River after the confluence of Yalfan and Abro rivers (Fig. 1).

In order to provide Hamedan's drinking water, this dam started its operation in 1964. Table 1 shows the dam's characteristics.

In this research, by using data of the 2002 elevationcapacity-area curves of Ekbatan dam reservoir and through area reduction method, the sediment distribution profile was estimated for the year 2012.

\section{Area reduction method}

Experimental area-reduction method, first presented by Borland and Miller (1958) was subsequently revised by Moody (Blanton and Ferrari 1992). The aim of the Borland and Miller technique is to establish volume/surface area/ depth relationships for reservoirs after sediment has been deposited therein (Annandale 1987). The calculation procedure of this empirical method was developed from resurvey data of 30 American reservoirs and consist of two main steps, viz. (Annandale 1984).

(a) Classification of a reservoir as one of four standard types, and

(b) An interactive calculations procedure to determine volume/surface area/depth relationships. 
Table 1 Technical feature of Ekbatan dam

\begin{tabular}{lllll}
\hline River & Dam type & Following elevation $(\mathrm{m})$ & Crest length $(\mathrm{m})$ & Total reservoir capacity (MCM) \\
\hline Abshineh & Gravity Dam & 79 & 673 & 40.2 \\
\hline
\end{tabular}
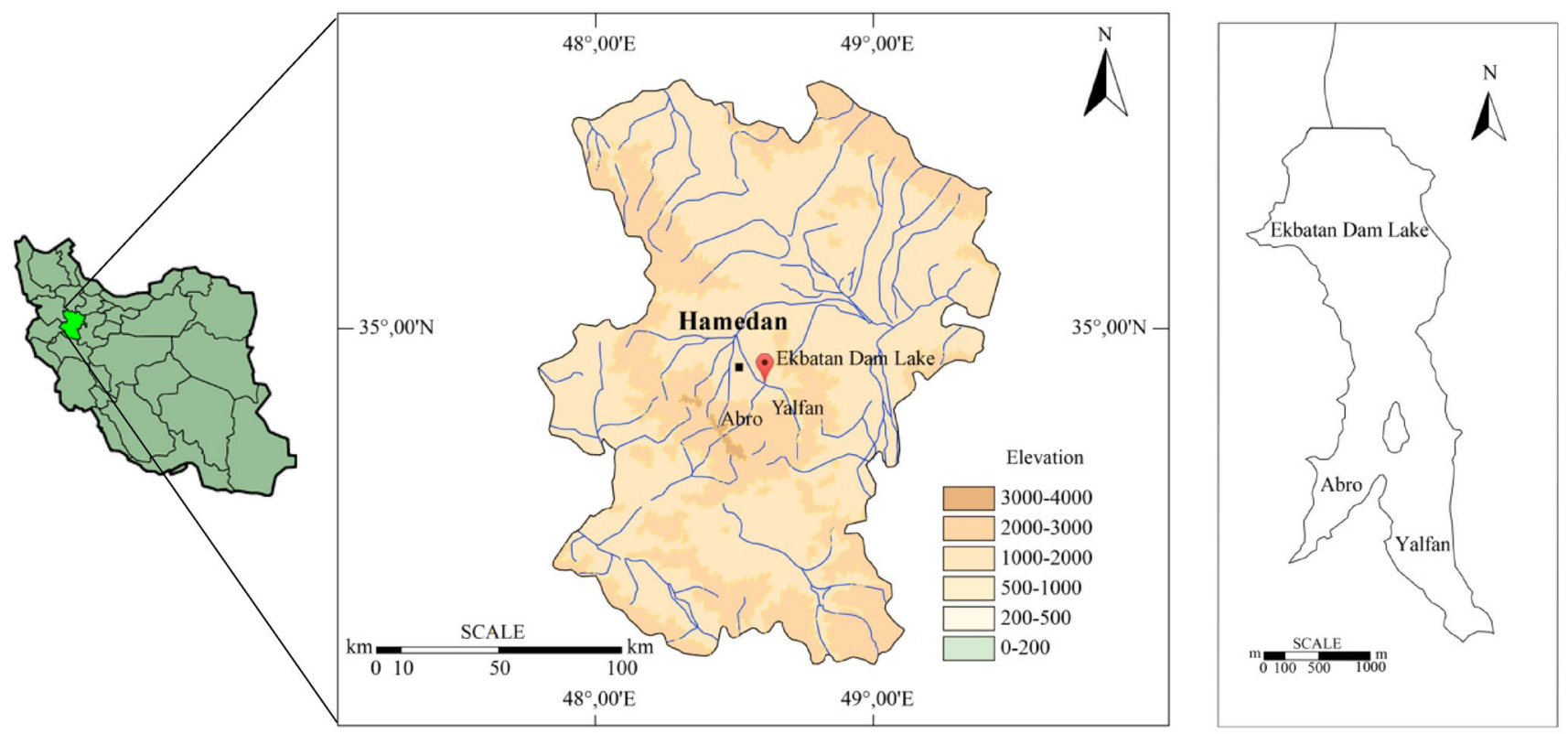

Fig. 1 Geographical location of Ekbatan dam Lake to Hamedan city

where $\mathrm{m}$ is the shape factor. The main equation in this method is:

$S=\int_{0}^{y_{0}} A d y+\int_{y_{0}}^{H} K a d y$

After integration:

$\frac{1-v_{0}}{a_{0}}=\frac{S-V_{0}}{H \times A}$

for resolving Eq. (2):

$h_{(p)}=\frac{1-v_{(p)}}{a_{(p)}}$

$h_{(p)}^{\prime}=\frac{S-V_{(y)}}{H \times A_{(y)}}$

where $S$ is the total input sediments to the reservoir during life span of reservoir and the bottom and above limits of the first integral count for the primary level of the river bed at the place of construction before and after sediment settlement, respectively. $A$ is the reservoir area in the different elevations. $d y$ is height increment, $H$ is the reservoir height at normal water level. $a$ is the approximate area of sediments which is measurable according to a difference, for the approximate of $p, h(p)$ is the dimensionless function of the whole settled sediments, and the capacity depth and
Table 2 Standard reservoir types (Borland and Miller 1958)

\begin{tabular}{lll}
\hline Standard classification & Reservoir type & Value of “m” \\
\hline I & Lake & $3.5-4.5$ \\
II & Floodplain-foothill & $2.5-3.5$ \\
III & Hill & $1.5-2.5$ \\
IV & Gorge & $1.0-1.5$ \\
\hline
\end{tabular}

area of reservoir. $V(y)$ is the reservoir capacity in level $\mathrm{y}$ and $A(y)$ in the reservoir area in level of $\mathrm{y}$ and $k$ is the proportion coefficient to change the sediment in the approximate area into the real area obtained from Eq. (5).

$K=\frac{A_{0}}{a_{0}}$

In which $A_{0}$ is the reservoir area in height $h_{0} . a_{0}$ is the sediment in the approximate area in the new height zero. The approximate area is obtained through Eq. (6).

$a_{(p)}=C p^{m}(1-p)^{n}$

where the measures $C, \mathrm{~m}$ and $n$ are fixed coefficients determined according to the type of reservoir from Table 2. Of course, these measures are Borland and Miller: corrected measures which can be calibrated for each reservoir (Fig. 2). 
Fig. 2 Classification of reservoirs in terms of volume/ depth relationships

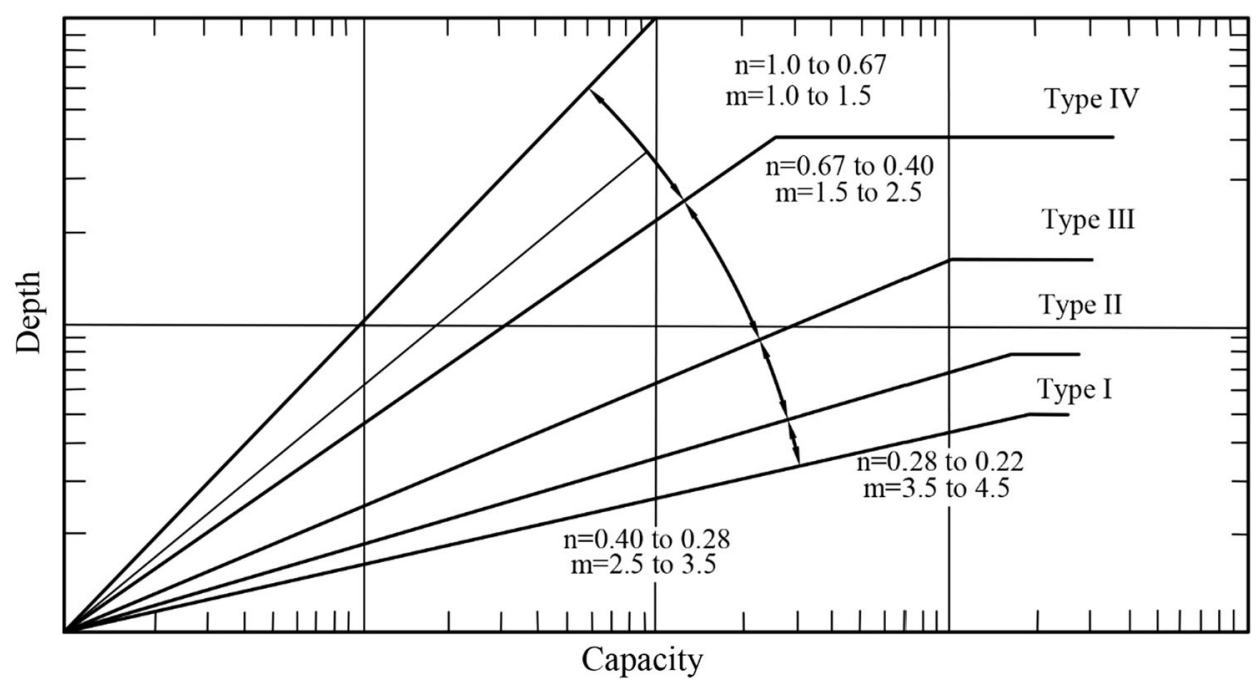

Table 3 Values $\mathrm{C}, \mathrm{m}$ and $\mathrm{n}$ on type of reservoir

\begin{tabular}{lrrl}
\hline Type & \multicolumn{1}{l}{ C } & \multicolumn{1}{l}{$\mathrm{m}$} \\
\hline I & 5.074 & 1.85 & 0.36 \\
II & 2.487 & 0.57 & 0.41 \\
III & 16.967 & -1.15 & 2.32 \\
IV & 1.486 & -0.25 & 1.34 \\
\hline
\end{tabular}

In the area reduction method, for determining the profile of sediment distribution, the following steps should be taken (Table 3) (Yang 1996):

Step 1: The depth of reservoir is drawn against its capacity in a logarithmic paper, to determine the reservoir shape factor (M) and then, the reservoir type is determined accordingly from Table 2 .

Step 2: The measures of dimensionless function $h_{(p)}$ for the different measures of approximate depth of $p$ are calculated from Eq. (4).

Step 3: Based on the relative depth $\mathrm{p}$ and also $F-p$ relation obtained from the graph in Fig. 3, the value/s of $\mathrm{h}_{(\mathrm{p})}$ is/are drawn in the Cartesian system, where these two curves cross is the new zero level in dam.

The values of $F$ dimensionless function, for different values of the relative depth, is calculated by Eq. (7).

$F=\left(S-V_{h}\right)\left(H \times A_{h}\right)$

where $F$ is dimensionless function from total deposited sediment, the capacity, the depth and reservoir area. $S$ is the total input sediments to the reservoir during life span of reservoir and the bottom and above limits of the first integral count for the primary level of the river bed at the place of construction before and after sediment settlement, respectively, $H$ is the reservoir height at normal water level, $V_{h}$ is reservoir capacity in the heigh $h$ and $A_{h}$ is the reservoir area in the heigh $h$.

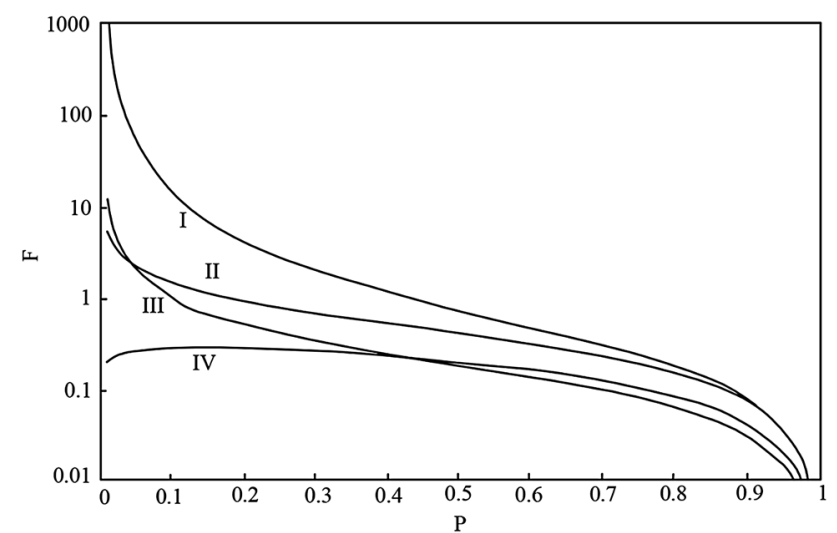

Fig. 3 Curves to determine the depth of sediment of dams (Strand and Pemberton 1982)

Step 4: By using the reservoir's capacity-depth curve, the volume of the existing sediments under zero level is determined and then according to Eq. (1), the sediment volume in the different depths are calculated. It should be noticed that this method is a trial and error and if the obtained sediment volume has a high discrepancy with input sediments, the proportion coefficient is calculated again from Eq. (8).

$K_{2}=K_{1} \frac{S}{S_{1}}$

where $K_{2}$ is the new proportion coefficient and $K_{1}$ is the previous proportion coefficient and $S_{1}$ is the accumulative volume of sediments.

Then, these measures are compared to those obtained from hydrograph and the amount of root mean square error is calculated according to Eq. (9). 
$R M S E=\sqrt{\frac{\sum\left(v-v_{i}\right)^{2}}{n}}$

In which $v_{i}$ and $v$ are the measured volume and real volume of reservoir in the different levels, respectively.

\section{Genetic algorithms}

GAs were first presented systematically by Holland, the basic ideas of analysis and design based on the concepts of biological evolution can be found in the work of Rechenberg (Mitchell 1998; Antoniou and Lu 2007). The Solution of an optimization problem by GAs starts with a population of random strings denoting several (population of) design vectors. The population size in GAs is usually fixed. Each string (or design vector) is evaluated to find its fitness value. The population (of designs) is operated by three operators-selection, crossover, and mutation-to produce a new population of points (designs).

\section{Selection}

The selection component of a GA is designed to use fitness to guide the evolution of chromosomes by selective pressure (Kia 2009). Chromosomes are therefore selected for recombination on the basis of fitness. Those with higher fitness should have a greater chance of selection than those with lower fitness, thus creating a selective pressure towards more highly fit solutions. This allocates each chromosome a probability of being selected proportional to its relative fitness, which is its fitness as a proportion of the sum of fitnesses of all chromosomes in the population (Goldberg 1989). There are many different selection schemes. Random stochastic selection explicitly selects each chromosome a number of times equal to its expectation of being selected under the fitness proportional method. Tournament selection first selects two chromosomes with uniform probability and then chooses the one with the highest fitness. Truncation selection simply selects at random from the population having first eliminated a fixed number of the least fit chromosomes (Davis 1991).

\section{Crossover}

The crossover operator represents the mixing of genetic material from two selected parent chromosomes to produce one or two child chromosomes. After two parent chromosomes have been selected for recombination, a random number in the interval $(0,1)$ is generated with uniform probability and compared to a pre-determined "crossover rate". If the random number is greater than the crossover rate, no crossover occurs and one or both parents pass unchanged on to the next stage or recombination. If the crossover rate is greater than or equal to the random number, then the crossover operator is applied. One commonly used crossover operator is one-point crossover. A crossover point between 0 and $n$ is chosen with uniform probability. Child chromosomes are then constructed from the characters of the first parent occurring before the crossover point and the characters of the second parent occurring after the crossover point. We illustrate this on a length 10 bit-string encoding as follows: (McCall 2005).

Parent one: 111101000110

Parent two: 0001000111100

Crossover point: $\uparrow$

Child one: 11110011100

Child two: 0001101000110

There are many alternative forms of crossover operation. One-point crossover generalises straightforwardly to 2- and multi-point crossover operations, where a sequence of crossover points is chosen along the chromosome length and the child chromosomes are constructed from the allele values of the two parents, interchanging at each crossover point. Uniform crossover constructs a child by selecting uniformly between parent allele values at each locus. Algorithms also differ with respect to whether one or more children are created from the crossover operation. After crossover, the resultant chromosome(s) will be passed on to the mutation stage.

\section{Mutation}

Mutation operators act on an individual chromosome to flip one or more allele values. In the case of bit-string chromosomes, the normal mutation operator is applied to each position in the chromosome. A random number in the interval $(0,1)$ is generated with uniform probability and compared to a predetermined "mutation rate". If the random number is greater than the mutation rate, no mutation is applied at that position. If the mutation rate is greater than or equal to the random number, then the allele value is flipped from 0 to 1 or vice versa. Mutation rates are typically very small (McCall 2005).

The new population is further evaluated to find the fitness values and tested for the convergence of the process. One cycle of production, crossover, and mutation and the evaluation of the fitness values is known as a generation in GAs. If the convergence criterion is not satisfied, the population is iteratively operated by the three operators and the resulting new population evaluated for the fitness values. The procedure is continued through several generations until the convergence criterion is satisfied and the process is terminated (Rao 2009). 
In the genetic algorithms the following steps should be taken (Chambers 2001):

Step 1: Randomly generate a population of genomes represented as bit strings.

Step 2: Assign a fitness value to each individual in the population.

Step 3: Selection:

(a) Retain the top $5 \%$ of the current population

(b) Randomly choose mating-pairs

Step 4: Crossover: randomly exchange genetic material between the two genomes in each mating pair to produce one child.

Step 5: Mutation: randomly mutate (invert) bit(s) in the genomes of the children.

Step 6: Repeat from step 2 with this new population until some termination criteria is fulfilled.

In this study, first based on area reduction method a model was made by using MATLAB software, area reduction method is added as a function to the genetic algorithms and calibrated by GA. Then sediment distribution profile of 2012 was estimated through area reduction method before and after calibration. Figure 4 shows flowchart of method that used in this study.

\section{Results and discussion}

In area reduction method previous year's elevation-areacapacity curves are used in order to calculate sedimentation distribution. In this study by using data of the 2002 elevation-capacity-area curves of Ekbatan dam reservoir and through area reduction method, the sediment distribution profile was estimated for the year 2012. The volume of sediment that entered into Ekbatan dam reservoir from year 2002 to year 2012 is 4.31 MCM.

The shape factor was adopted as the major criteria for development of empirically derived design curves for use in distributing sediment (Ferrari 2008). The shape of the reservoir is defined by the depth to capacity relationship where " $\mathrm{m}$ " is the reciprocal of the slope of the depth versus capacity plot on a logarithmic paper (USBR 1962). Considering that $\mathrm{m}=3.16$ the reservoir is from type II.

Simulation program in matlab was prepared so that if the errors in calculating the volume of the reservoir were less than 0.01 the program would stop and print the results. A function simulation method was added to optimization model and as a result a simulation-optimization model was obtained.

\section{Area reduction results before calibration}

Figure 5 shows the area reduction method prediction curves before calibration. According to Fig. 5, predicted volume curve by area reduction method from elevation 1915 to 1945 and 1965 to 1972 is not acceptable.

\section{Calibration result}

Table 4 shows the RMSE for sediment distribution using the Area Reduction method before and after calibrating parameters $(\mathrm{C}, \mathrm{m}, \mathrm{n})$ for the sediment distribution in Ekbatan dam. According to the table after calibration, the RMSE decreased around $46.7 \%$.

\section{Area reduction results after calibration}

Figure 6 shows the area reduction method prediction curves after calibration. According to Fig. 6, predicted

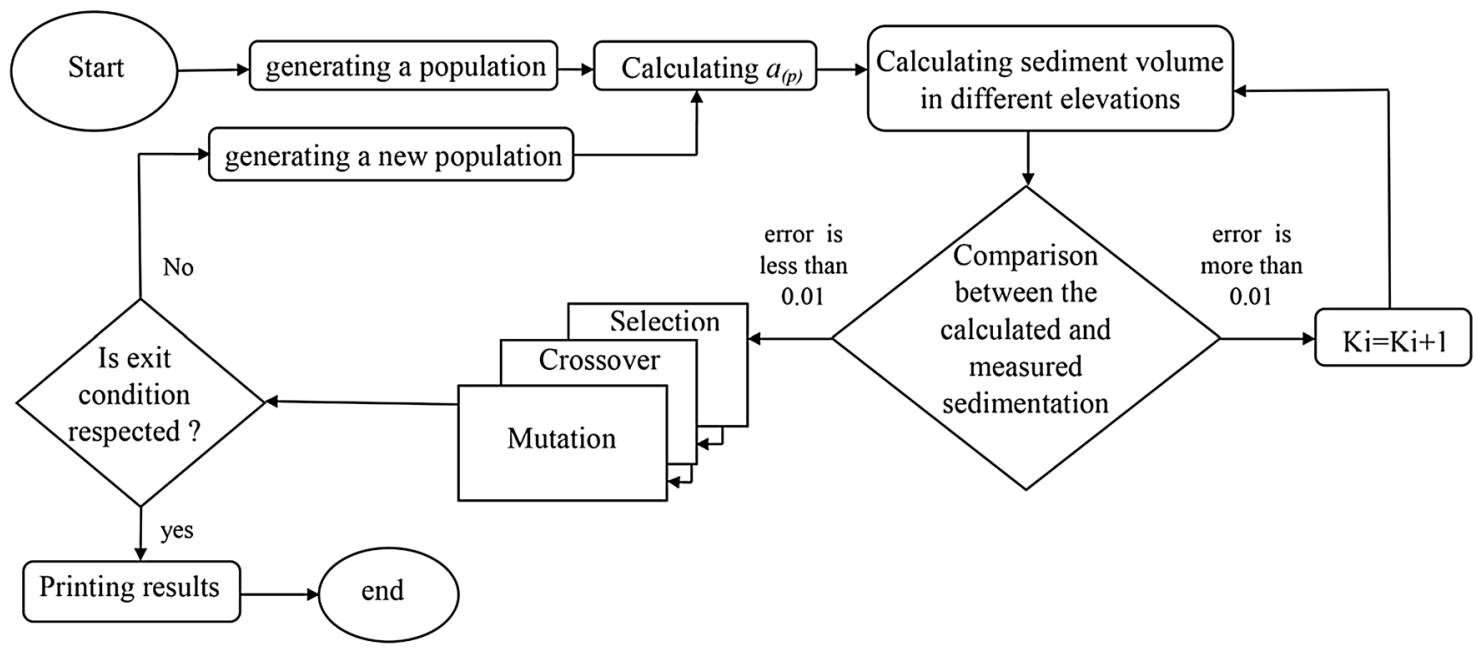

Fig. 4 Flowchart of calibration the area-reduction method using genetic algorithms 


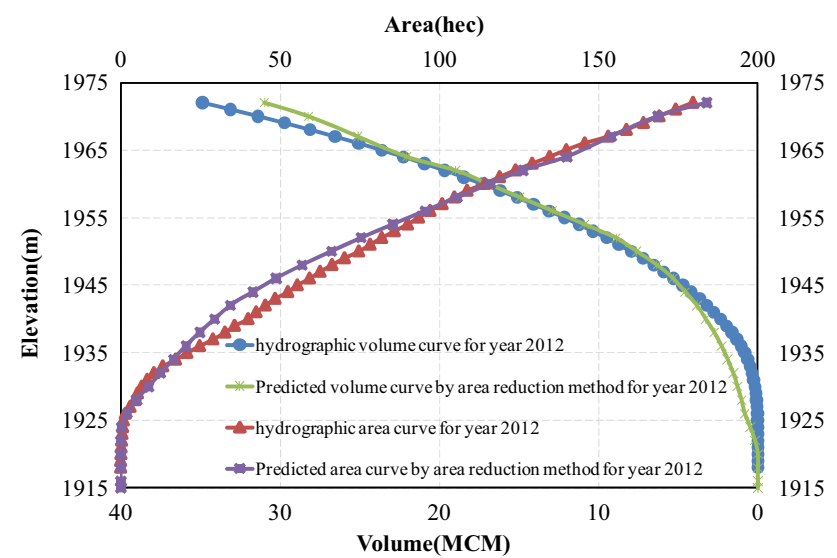

Fig. 5 Area reduction method prediction elevation-area-capacity curves before calibration

Table 4 Comparing the parameters of area reduction method before and after calibration

\begin{tabular}{lll}
\hline & $\begin{array}{l}\text { After } \\
\text { calibrated }\end{array}$ & $\begin{array}{l}\text { After } \\
\text { calibrated }\end{array}$ \\
\hline RMSE & 1.5 & 0.8 \\
\hline
\end{tabular}

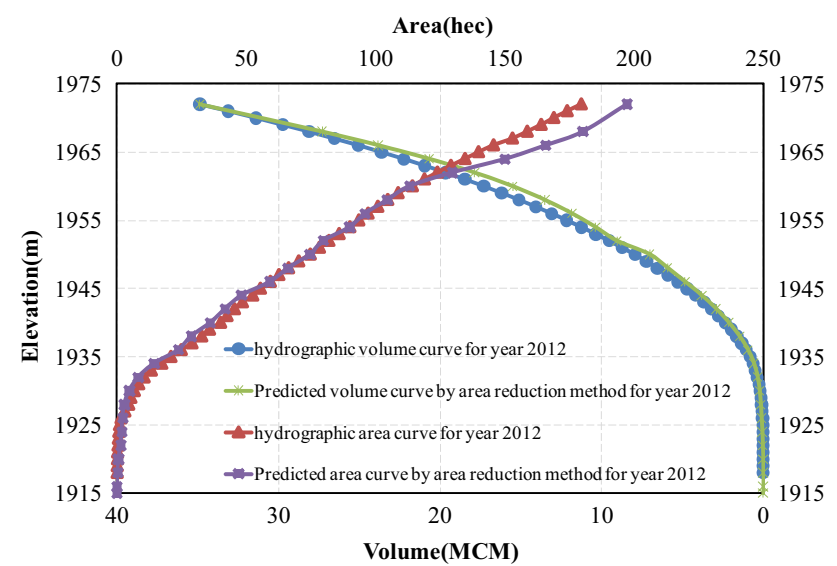

Fig. 6 Area Reduction method prediction elevation-area-capacity curves after calibration

volume curve by area reduction method is more compatibile with volume curve of the year 2012 .

So it is to say that calibrating area reduction method through Genetic algorithms led to obtain a better prediction of elevation-area-capacity curves.

\section{Predicted elevation-area-capacity curves for next years}

The useful life or design life is a period that the sediment deposited does not affect the economic feasibility and

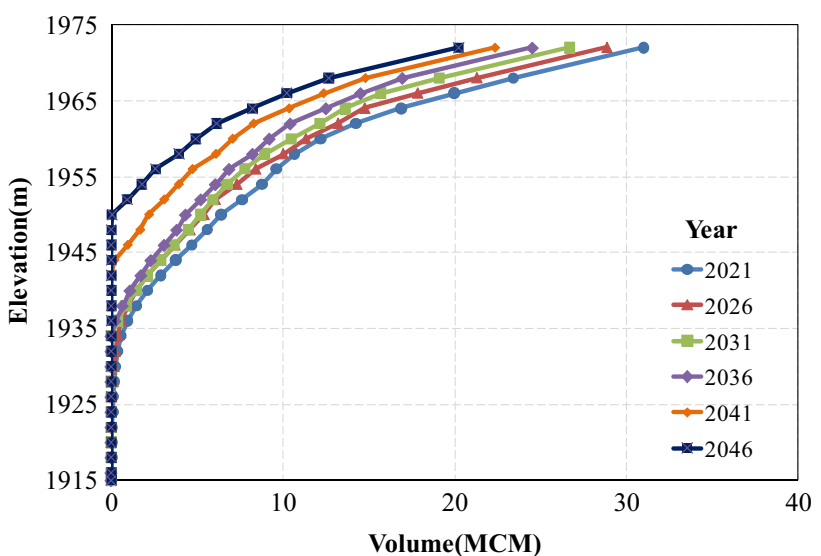

Fig. 7 Predicted elevation-area-capacity curves for next years

sustainability of water resources demand. In general, useful life of the reservoir is the time period when the reservoirs depleted $50 \%$ of its storage capacity or the dead storage is completely filled with sediment (Gill 1979). Figure 7 shows elevation-capacity curves predicted in years 2021, 2026, 2031, 2036, 2041 and 2046 with optimized coefficients. According to Fig. 7, $50 \%$ of volume of Ekbatan dam will be filled by sediment in 2046 .

\section{Sensitivity analysis}

In most practical problems, we are interested not only in optimal solution of the problem, but also in how the solution changes when the parameters of the problem change. Sensitivity analysis is used to determine how "sensitive" a model is to changes in the value of the parameters of the model and to changes in the structure of the model (Breierava and Choudhari 2001).

The simplest form of sensitivity analysis is to simply vary one value in the model by a given amount, and examine the impact that the change has on the model's results.

Figure 8 shows objective function changes in regard to iteration different rates in three phases of Sensitivity Analysis in Ekbatan dam.

According to Fig. 8, the most appropriate range for iteration parameter is $15-20$.

Figure 9 shows objective function changes in regard to different numbers of initial population in three phases of Sensitivity Analysis operation for the Ekbatan dam.

According to Fig. 9, 50-60 is the most appropriate efficiency range for the initial people. Figure 10 shows objective function changes in regard to different rates of mutation.

According to the Fig. 10, the most appropriate range for this parameter is $0.40-0.50$. 


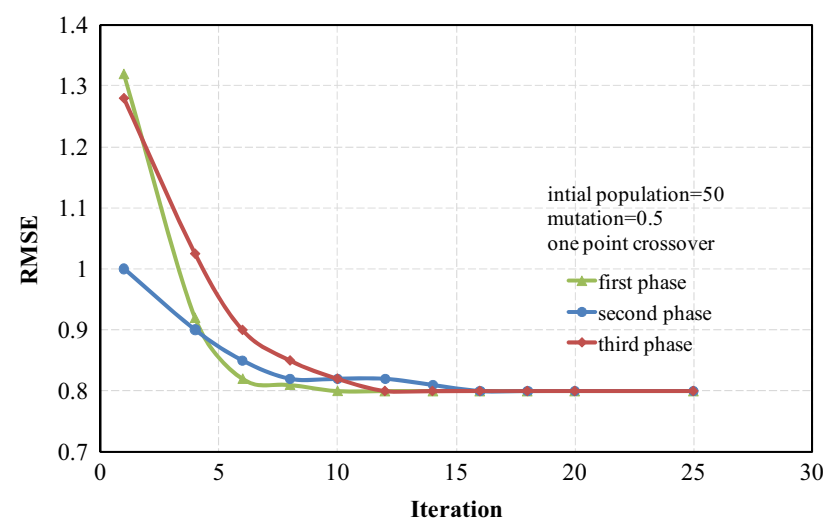

Fig. 8 Sensitivity analysis of GA for iteration

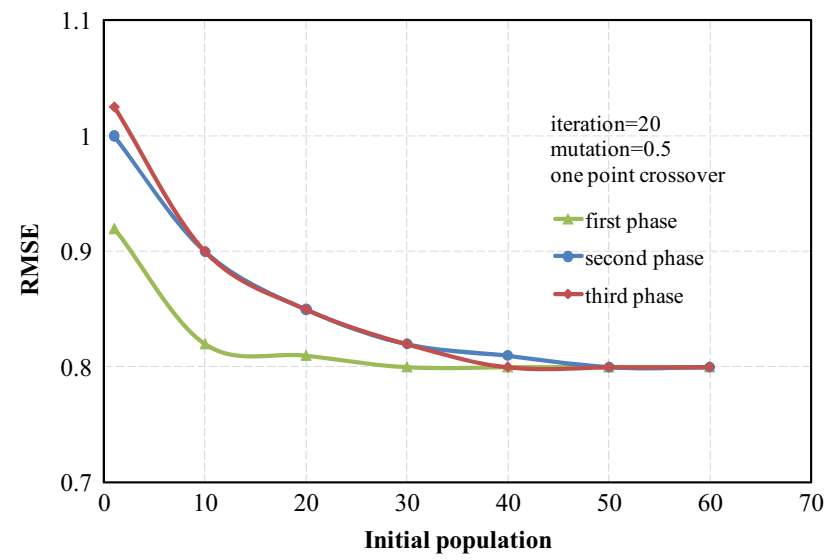

Fig. 9 Sensitivity analysis of GA for initial population

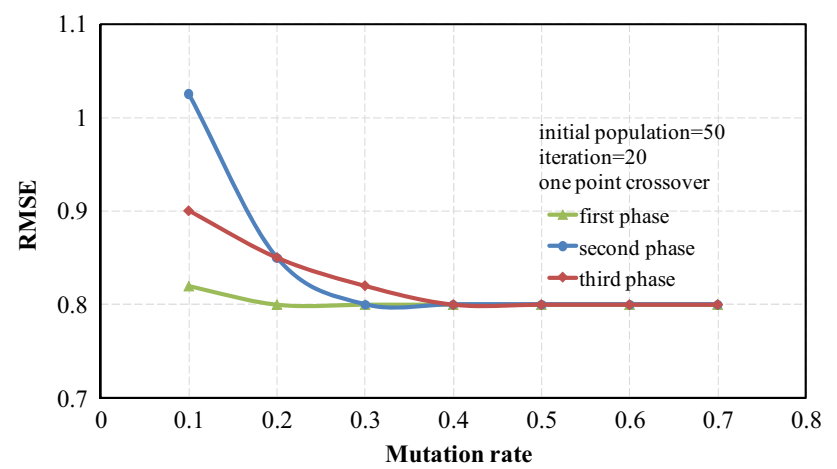

Fig. 10 Sensitivity analysis of GA for mutation rate

\section{Conclusions}

In order to estimate sediment distribution manner in Ekbatan dam reservoir, we used area reduction experimental method. In this method RMSE was 1.5. C, m, n parameters were optimized with genetic algorithms to reduce sedimentation estimate error and resulted elevation- area-capacity curves was compared with 2011 hydrography curves. RMSE declined by $46.7 \%$.

Elevation-area-capacity curves of Ekbatan dam in 2021, 2026, 2031, 2036, 2041 and 2046 were predicted through optimized parameters. The results showed that $50 \%$ of volume of Ekbatan dam will be filled by sediment in 2046.

Then the most appropriate ranges for iteration parameters (15-20), for initial people parameters (50-60) and mutation rate $(0.4-0.5)$ were found through sensitivity analysis.

A comparison between predicted results through area reduction method with hydrography results showed that using genetic algorithms can considerably rise the accuracy of area reduction experimental method.

\section{References}

Annandale GW (1984) Predicting the distribution of deposited sediment in Southern African Reservoir. Nat Hydrol Symp 144:549-557

Annandale GW (1987) Development in water science, reservoir sedimentation (1st ed). BV Rand Afrikaans University: Elsevier Science Publishers

Antoniou A, Lu WS (2007) Practical optimization algorithms and engineering applications. Springer Science + Business Media LLC, New York

Blanton III JO, Ferrari RL (1992) Lake Texana 1991 Sedimentation Survey. Bureau of Reclamation, Technical Service Center, Denver, Colorado

Borland WM, Miller CR (1958) Distribution of sedimentation in large Reservoirs. J Hydraul Div ASCE HY2

Breierava L, Choudhari M (2001) An introduction to sensitivity analysis. Massachusetts Institute of Technology, Cambridge

Chambers L (2001) The practical handbook of genetic algorithms applications. Chapman \& Hall, London

Davis L (1991) Handbook of genetic algorithms. Van Nostrand Reinhold, NewYork

Emadi AR, Khademi M, Mohamadiha A (2012) Application of simulated annealing algorithm in calibration of area reduction method in sediment distribution of dams reservoir (case study: Karaj Dam). J Water Soil Conserv 19:173-188

Engelbrecht AP (2002) Computational intelligence an introduction. Wiley, New York

Ferrari RL (1998) Prineville Reservoir 1998 Sedimentation Survey. Bureau of Reclamation. Technical Service Center, Denver, Colorado

Ferrari RL (2008) Altus Reservoir 2007 Sedimentation Survey. Bureau of Reclamation. Technical Service Center, Denver

Gharaghezlou M, Masoudian M, Fendereski R (2014) Calibrating the experimental area reduction method in assessing the distribution of sediments in Droodzan Reservoir Dam in Iran. J Civ Eng Urban 4:54-58

Gill MA (1979) Sedimentation and useful life of reservoirs. J Hydrol 44:89-95

Goldberg DE (1989) Genetic algorithms in search, optimization and machine learning. Addison-Wesley, MA

Haupt RL, Haupt SE (2004) Practical genetic algorithms. Wiley, New Jersey 
Holland JH (1975) Adaptation in natural and artificial systems: an introductory analysis with applications to biology, control, and artificial intelligence. University of Michigan Press, Ann Arbor

Kia SM (2009) Genetic algorithms in Matlab. Kian Rayaneh Sabz, Tehran

Lara JM (1971) The 1967 Altus Reservoir Sediment Survey. United States Department of the Interior, Hydrology Branch, Denver, Colorado

McCall J (2005) Genetic algorithms for modelling and optimisation. J Comput Appl Math 184:205-222

Mitchell M (1998) An introduction to genetic algorithms. MIT Press, Cambridge

Mohammadiha A, Emadi A, Mohammad Vali Samani J (2010) Auto calibration of area-reduction method in sediment distribution of dam reservoir using genetic algorithm. Iran J Soil Water Res 25:356-364

Mohammadzadeh Habili J, Mousavi F (2008) Improvement of the reservoir shape factor method and evaluation of its changes due to sedimentation. J Water Soil 22:407-416

Mousavi SF, Haydarpour M, Shabanlou S (2006) Investigation of sediments in the Zayandehrud reservoir through area-increment and area-reduction empirical models. Water Wastewater 17:76-82

Pelikan M, Goldberg DE, Lobo FG (1999) A survey of optimization by building and using probabilistic models. University of Illinois Genetic Algorithms Laboratory, Urbana
Pierre YJ (2002) River mechanics. Cambridge University Press, New York

Rao SS (2009) Engineering optimization, theory and practice, 4th edn. Wiley, New Jersey

Shafai Bajestan M (2011) Hydraulics of sediment transport, 2nd edn. Shahid Chamran University Press, Ahwaz

Shafiee AH, Safamehr M (2011) Study of sediments water resources system of Zayanderud Dam through area increment and area reduction methods. Proc Earth Planet Sci 4:29-38

Strand RI, Pemberton EL (1982) Reservoir sedimentation. US Bureau of Reclamation, Denver

United States Bureau of Reclamation (1962) Revision of the procedure to compute sediment distribution in large reservoirs. Sedimentation Section, Hydrology Branch

Vose MD (1999) The simple genetic algorithm. MIT Press, Cambridge

Wu W (2007) Computational river dynamics. National Center for Computational Hydroscience and Engineering, University of Mississippi, MS, USA

Jain SK (2003) Water resources systems planning and management. Elsevier Science, London

Yang CT (1996) Sediment transport: theory and practice. Mc GrawHill, New York 